$11-16$

\title{
Obesity and early reoperation rate after elective lumbar spine surgery: a population- based study
}

Authors Cinzia Gaudelli ${ }^{1}$, Ken Thomas ${ }^{2}$

Institutions $\quad{ }^{1}$ McCaig Institute for Bone and Joint Health, University of Calgary, Alberta, Canada

${ }^{2}$ Departments of Surgery and Clinical Neurosciences, University of Calgary, Alberta, Canada

\begin{tabular}{|c|c|}
\hline $\begin{array}{l}\text { Final class of } \\
\text { evidence-prognosis }\end{array}$ & \\
\hline \multicolumn{2}{|l|}{ Study design } \\
\hline Prospective Cohort & \\
\hline Retrospective Cohort & 。 \\
\hline Case control & \\
\hline Case series & \\
\hline \multicolumn{2}{|l|}{ Methods } \\
\hline $\begin{array}{l}\text { Patients at similar point in } \\
\text { course of treatment }\end{array}$ & 。 \\
\hline$F / U \geq 85 \%$ & 。 \\
\hline $\begin{array}{l}\text { Similarity of treatment } \\
\text { protocols for patient groups }\end{array}$ & 。 \\
\hline $\begin{array}{l}\text { Patients followed up long } \\
\text { enough for outcomes to occur }\end{array}$ & 。 \\
\hline $\begin{array}{l}\text { Control for extraneous risk } \\
\text { factors }\end{array}$ & \\
\hline Overall class of evidence & III \\
\hline $\begin{array}{l}\text { The definiton of the different } \\
\text { classes of evidence is available } \\
\text { on page } 55 \text {. }\end{array}$ & \\
\hline
\end{tabular}

\section{ABSTRACT}

Study design: Population-based retrospective cohort study.

Clinical question: Are patients with a body mass index (BMI) of 35 or more who undergo elective lumbar spine surgery at increased risk of postsurgical complications, as evidenced by reoperation within a 3-month period?

Methods: The Alberta Health and Wellness Administrative database was queried to identify patients who underwent elective lumbar spine surgery over a 24-month period. This same database was used to classify subjects as obese (BMI $\geq 35$ ) and non-obese (BMI <35) and to determine who underwent repeated surgical intervention. The rate of reoperation was determined for both the obese and non-obese groups; further analyses were performed to determine whether certain subjects were at increased risk of reoperation.

Results: The point estimate for relative risk for requiring reoperation was 1.73 (95\% confidence interval, 1.03-2.90) for obese subjects compared with non-obese subjects. The adjusted point estimate shows that deformity correction surgery is predictive for early reoperation while obesity is not.

Conclusions: In obese subjects we observed an increased complication rate after elective lumbar spine surgery, as evidenced by reoperation rates within 3 months. When we considered other possible associations with reoperation, in adjusted analysis, deformity surgery was found to be predictive of early reoperation.

The authors have no conflicts of interest to declare.

This study was funded by Calgary Surgical Research Development Fund.

This study has been approved by the University of Calgary Office for Medical Bioethics. 


\section{STUDY RATIONALE AND CONTEXT}

There is conflicting evidence regarding whether obese patients have higher complication rates after spine surgery than non-obese patients [1-9]. This is of particular concern given that obese patients have a greater incidence of chronic back pain with associated neurological signs and symptoms, thus it is expected that a higher proportion of obese patients will undergo lumbar spine surgery [10].

\section{METHODS}

Study design: Population-based retrospective cohort study.

Primary question: Are patients with a body mass index (BMI) $\geq 35$ undergoing elective lumbar spine surgery at increased risk of postoperative complications, as defined by reoperation within a 3-month period?

Secondary questions: Are any patient subgroups at a higher risk of reoperation? Subgroups, identified a priori, included gender, age, location of surgery (urban versus rural setting), and type of procedure performed (decompression, decompression with instrumented fusion, deformity correction, and arthroplasty).

Fig 1 Subject selection.

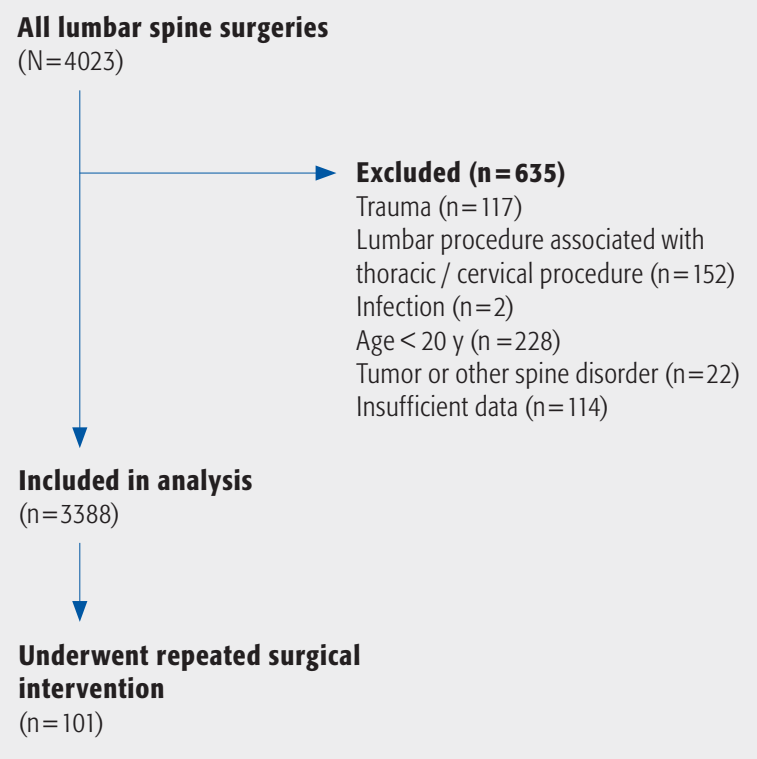

\section{Inclusion criteria:}

- Age $\geq 20$ years

- Elective lumbar spine surgical procedure

- Surgery between July 1, 2007, and June 30, 2009

- Surgery funded by Alberta Health and Wellness, in Alberta, Canada, the provincial medical insurance entity

\section{Exclusion criteria:}

- Trauma

- Underlying malignancy

- Infection

- Incomplete data

Patient population: We identified all patients having had a lumbar spine procedure funded by Alberta Health and Wellness during the study period. The obese group was defined as those with a BMI $\geq 35$, corresponding to class II and III obesity as per the World Health Organization classification system. These patients were identified using a BMI billing code; we did not stratify reoperation rates according to differing BMI cut-points due to availability of data.

\section{Clinical risk factors:}

- Age

- Gender

- Procedure (decompression only, decompression with instrumented fusion, deformity correction, or arthroplasty)

Other confounding factors, such as medical comorbidities and smoking, were not available through this database.

Outcomes: The primary outcome measure was the rate of reoperation, for any reason, within 3 months of the index procedure.

Analysis: The data was verified to ensure all subjects had a complete dataset. We calculated the reoperation rates for both obese and non-obese subjects who underwent elective lumbar spine surgery. The relative risk (RR) of reoperation for obese subjects and the $95 \%$ confidence interval $(\mathrm{CI})$ was determined $(\mathrm{R} R=$ risk of reoperation in obese group/risk of reoperation of entire cohort; $95 \%$ $\mathrm{CI}=(\mathrm{x}-1.96 \sigma / \sqrt{ } \mathrm{n}, \mathrm{x}+1.96 \sigma / \sqrt{ } \mathrm{n})$. We performed subgroup analyses in the same manner. Calculations were performed using SPSS v 18 (SPSS Inc, Chicago, IL, USA). 


\section{RESULTS}

- 4023 lumbar spine procedures were performed, 635 were excluded, thus leaving 3388 for analysis (Fig 1).

- $52.2 \%$ of the subjects were male and most patients $(61.5 \%)$ were aged between 40 and 74 years. $61.8 \%$ had isolated decompression surgery while $33.4 \%$ had some form of instrumentation of fusion (Table 1).

- 101 subjects (3\%) required reoperation in the 3 months after elective lumbar spine surgery. The obese group had a statistically significant higher reoperation rate compared with the non-obese group $(4.8 \%$ versus $2.8 \%$ ) (Table 1). This corresponds to RR of 1.73 (95\% CI, 1.03-2.90) (Fig 2).
- Using in a logistic regression analysis, controlling for age, gender and type of procedure performed, the odds ratio for obese patients requiring reoperation was 1.57 (95\% CI, 0.89-2.77). The variable predictive for early reoperation was type of procedure; where instrumented fusion had an odds ratio of 1.64 (95\% CI, 1.05-2.56) and deformity correction had an odds ratio of 4.46 (95\% CI, 2.34-8.53) (Table 2).

- The most common reason for reoperation, according to billing codes, was repeated nerve root compression followed by infection (Table 3). There were no differences between reason for reoperation and time to reoperation between obese and non-obese groups.

Table 1 Demographic data and differences in reoperation rates between obese and non-obese subjects.

\begin{tabular}{|c|c|c|c|c|c|c|}
\hline & & $\begin{array}{l}\text { No. of } \\
\text { subjects }\end{array}$ & BMI > $35(\%)$ & $\begin{array}{l}\text { Total reoperations } \\
(\%)\end{array}$ & $\begin{array}{l}\text { Reoperations } \\
\text { non-obese (BMI < 35) } \\
\text { subjects }(\%)\end{array}$ & $\begin{array}{l}\text { Reoperations } \\
\text { obese }(\mathrm{BMI} \geq 35) \\
\text { subjects }(\%)\end{array}$ \\
\hline Total & & 3388 & $332(9.8)$ & $101(3.0)$ & $85(2.8)$ & $16(4.8)$ \\
\hline \multirow[t]{2}{*}{ Gender } & Male & 1770 & $148(8.4)$ & $43(2.4)$ & $42(2.6)$ & $1(0.7)$ \\
\hline & Female & 1620 & $184(11.4)$ & $59(3.6)$ & $59(4.1)$ & $14(7.6)$ \\
\hline \multirow[t]{5}{*}{ Age, y } & $20-29$ & 245 & $19(7.8)$ & $9(3.7)$ & $8(3.5)$ & $1(5.3)$ \\
\hline & $30-44$ & 791 & $73(9.2)$ & $28(3.5)$ & $25(3.5)$ & $3(4.1)$ \\
\hline & $45-59$ & 1036 & $120(11.6)$ & $27(2.6)$ & $24(2.6)$ & $3(2.5)$ \\
\hline & $60-74$ & 927 & $104(11.2)$ & $39(4.2)$ & $34(4.1)$ & $5(5)$ \\
\hline & $75+$ & 391 & $19(4.9)$ & $13(3.3)$ & $10(2.7)$ & $3(15.7)$ \\
\hline \multirow{4}{*}{$\begin{array}{l}\text { Type of } \\
\text { surgery }\end{array}$} & Decompression & 2095 & $166(7.9)$ & $47(2.2)$ & $39(2.0)$ & $8(4.8)$ \\
\hline & $\begin{array}{l}\text { Decompression with } \\
\text { instrumentation or fusion }\end{array}$ & 1130 & $159(14.1)$ & $41(3.6)$ & $35(3.6)$ & $6(3.8)$ \\
\hline & Arthroplasty & 25 & $0(0)$ & $0(0)$ & $0(0)$ & $0(0)$ \\
\hline & Deformity correction & 138 & $8(5.8)$ & $13(9.4)$ & $12(9.2)$ & $1(12.5)$ \\
\hline
\end{tabular}


Fig 2 Unadjusted relative risk of reoperation within 3 months of elective lumbar surgery (solid lines represent 95\% confidence intervals).

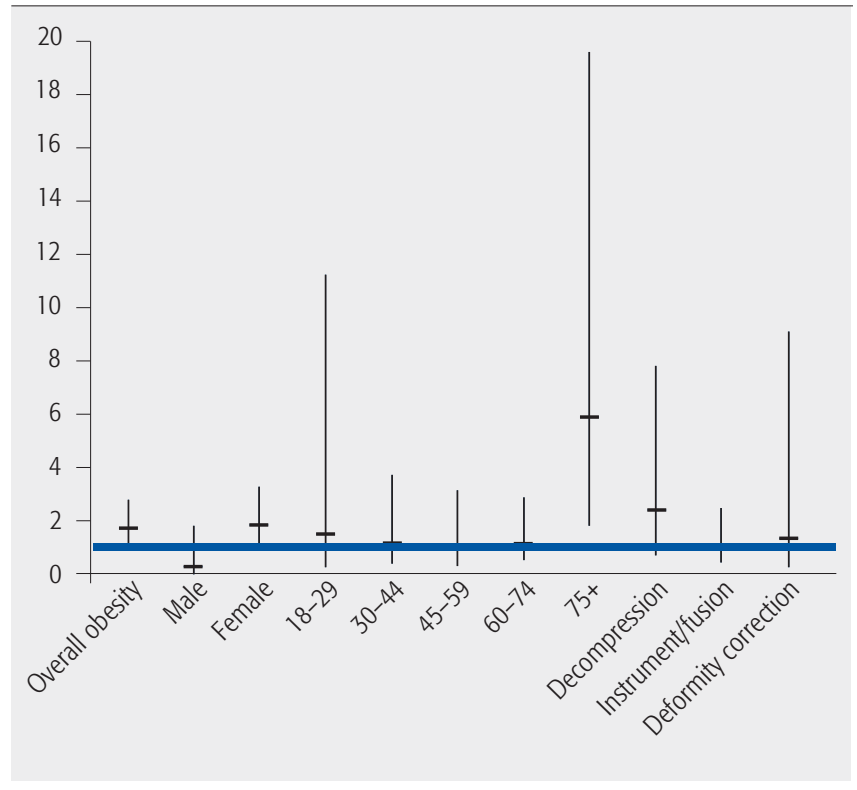

Table 2 Adjusted point estimates (odds ratios) for early reoperation.

\begin{tabular}{lll}
\hline Variable & Odds ratio & $\begin{array}{l}\text { 95\% Confidence } \\
\text { interval }\end{array}$ \\
\hline Obesity & 1.57 & $(0.89-2.77)$ \\
\hline Age & 0.99 & $(0.98-1.01)$ \\
\hline Gender: female & 1.39 & $(0.92-2.09)$ \\
\hline Procedure: instrumented fusion & 1.64 & $(1.05-2.56)$ \\
\hline Procedure: deformity correction & 4.46 & $(2.34-8.53)$ \\
\hline
\end{tabular}

Table 3 Explanation for reoperation stratified by obesity status.

\begin{tabular}{llllll}
\hline & $\begin{array}{l}\text { Infection } \\
(\mathbf{\%})\end{array}$ & $\begin{array}{l}\text { Repeated nerve } \\
\text { compression (\%) }\end{array}$ & $\begin{array}{l}\text { Deformity } \\
(\mathbf{\%})\end{array}$ & $\begin{array}{l}\text { Mechanical } \\
\text { failure (\%) }\end{array}$ & $\begin{array}{l}\text { Mean No. of days to reoperation from index } \\
\text { procedure }\end{array}$ \\
\hline Obese & $8(2.4)$ & $7(2.1)$ & $0(0)$ & $0(0)$ & 12.5 \\
\hline Non-obese & $26(0.9)$ & $57(1.9)$ & $1(0.03)$ & $1(0.03)$ & 16.8 \\
\hline
\end{tabular}




\section{DISCUSSION}

- While some studies have shown an increased risk of complications for obese patients after lumbar spine surgery, others have shown the contrary. The point estimate from this population-based study suggests that obese subjects have nearly double the reoperation rate.

- The adjusted estimate suggests that instrumented fusion and deformity correction surgery is predictive for early reoperation.

- We report on a complete population. The one-payer health insurance system in Alberta allowed the capture of all elective lumbar spine surgical patients in the province.

- Given the restrictions imposed by the data available, we could not account for comorbid conditions. Data quality was dependent on the accuracy submissions by the surgeons for billing purposes; incomplete or inconsistent entries were not included in the analysis to reduce bias.

- The reasons for reoperation were likely biased due to the higher fees associated with repeated decompression procedures compared with irrigation and debridement.

- Morbidly obese patients were overrepresented in this population $(9.8 \%)$ compared with the Canadian national average $(7.8 \%)$ [11].

\section{SUMMARY AND CONCLUSION}

Five percent of obese subjects required early reoperation after elective lumbar spine surgery. Compared with nonobese subjects, this corresponds to a point RR of 1.73 . When accounting for possible known confounders, deformity correction is associated with the largest risk for early reoperation.

\section{REFERENCES}

1. Andreshak TG, An HS, Hall J, et al (1997) Lumbar spine surgery in the obese patient. J Spinal Disord; 10(5):376-379.

2. Wimmer C, Gluch H, Franzreb M, et al (1998) Predisposing factors for infection in spine surgery: a survey of 850 spinal procedures. J Spinal Disord; 11(2):124-128.

3. Telfeian AE, Reiter GT, Durham SR, et al (2002) Spine surgery in morbidly obese patients. J Neurosurg Spine; 97(1 Suppl):20-24.

4. Olsen MA, Mayfield J, Lauryssen C, et al (2003) Risk factors for surgical site infection in spinal surgery. $J$ Neurosurg Spine; 98 (2 Suppl):149-155.

5. Gepstein R, Shabat S, Arinzon ZH, et al (2004) Does obesity affect the results of lumbar decompressive spinal surgery in the elderly? Clin Orthop Relat Res; 426:138-144.

6. Patel N, Bagan B, Vadera S, et al (2007) Obesity and spine surgery: relation to perioperative complications. $J$ Neurosurg Spine; 6(4):291-297.

7. Shamji MF, Parker S, Cook C, et al (2009) Impact of body habitus on perioperative morbidity associated with fusion of the thoracolumbar and lumbar spine. Neurosurgery; 65(3):490-498.

8. Peng CWB, Bendo JA, Goldstein JA, et al (2009) Perioperative outcomes of anterior lumbar surgery in obese versus non-obese patients. Spine J; 9(9):715-720.

9. Yadla S, Malone J, Campbell PG, et al (2010) Obesity and spine surgery: reassessment based on a prospective evaluation of perioperative complications in elective degenerative thoracolumbar procedures. Spine J; 10:581-587.

10. Fanuele JC, Abdu WA, Hanscom B, et al (2002) Association between obesity and functional status in patients with spine disease. Spine; 27(3):306-312.

11. Statistics Canada (2005) Measured adult body mass index (BMI) by sex, household population aged 18 and over excluding pregnant females, Canada and provinces (table) Canadian Statistics. Available at: www.statcan. gc.ca. Accessed June 11, 2010. 


\section{EDITORIAL PERSPECTIVE}

Gaudelli and Thomas present compelling data to show that morbidly obese patients are almost twice as likely to have spine reoperation within 3 months compared with non-obese subjects. Age, gender, and procedure type were known but there was no ability from the billing records to control for other comorbidities, such as smoking. While most studies would be limited by referral biases, one unique aspect of this cohort is that it is derived from a single-payer healthcare system in Alberta, Canada. This means that virtually all patients would be captured in this dataset, unless they traveled out of the province for care. This method of administrative data capture for a 'captive patient population' allows for powerful large group analyses. There are, however, inherent limitations to such a system and any studies emanating from it:

- Database studies can be performed only with what is collected and accounted for and thus is available in the database. As shown in this study there are potentially significant findings that raise further questions, for instance: what is the potential role of other comorbidities such as smoking, diabetes, chronic obstructive pulmonary disease, drug abuse, or osteoporosis? The authors readily acknowledge this limitation.

- If multiple risk factors are available in a dataset, a multivariate analysis can be helpful, unless the individual cell counts become too small. In this study, the sample size was large; however, reoperations were relatively rare, making the assessment of multiple variables in the same model not possible.
Gaudelli and Thomas deserve praise for having significantly contributed to our understanding of obesity as a risk factor for unintended reoperations. This is consistent with other recent publications on the same topic, which drew from a larger statebased registry [1] and much smaller hospital-based databases [2, 3], but did not have the benefit of longer-term follow-up. While none of these studies came close to the presented study population, the message is the same: expect significantly higher complication rates and unanticipated reoperation rates in lumbar surgery with morbidly obese patients. This also raises the predictable next question of how to respond to this insight. Avoid surgery until the obesity issue is improved in elective situations or improve surgical techniques to reduce risk? There is ample room for further research activity on this important topic.

1. Kalanithi PS, Arrigo R, Boakye M (2011) Morbid obesity increases cost and complication rates in spinal arthrodesis. Spine (Phila Pa 1976). [Epub ahead of print].

2. Koutsoumbelis S, Hughes AP, Girardi FP, et al (2011) Risk factors for postoperative infection following posterior lumbar instrumented arthrodesis. J Bone Joint Surg Am; 93(17):16271633.

3. Mehta AI, Babu R, Karikari IO, et al (2011) The distribution of body mass as a significant risk factor for lumbar spinal fusion postoperative infections. Spine (Phila Pa 1976). [Epub ahead of print]. 